\title{
De entidad biológica a monstruo social: Una construcción semiótica del coronavirus durante la pandemia de COVID-19
}

\author{
From a Biological Entity to a Social Monster. A Semiotic \\ Construction of the Coronavirus During the Covid-19 Pandemic
}

\author{
https://doi.org/10.22235/d35.2650 \\ Sebastián Moreno Barreneche \\ ORCID: 0000-0003-3551-7117 \\ Universidad ORT Uruguay
}

\section{RESUMEN*}

Durante la primera mitad del 2020, el 'nuevo coronavirus', una entidad biológica invisible al ojo humano, fue representado en múltiples imágenes, productos audiovisuales, descripciones, narrativas y otros modos de articulación visual y verbal. Muchas de estas articulaciones fueron producidas por organismos internacionales, gobiernos y medios de comunicación, entre otros actores sociales, con el objetivo de hacer más tangible la amenaza representada por el virus. Al mismo tiempo, estas representaciones ayudaron a moldear cómo las personas le atribuyeron un sentido al virus, tanto en términos cognitivos como emocionales. Con apoyo en la premisa de que la realidad social se construye en procesos e interacciones múltiples y dinámicos que implican la producción, la distribución y el consumo de sentido en varios niveles, este artículo examina desde una perspectiva semiótica uno de los modos en que el coronavirus fue representado durante la pandemia del COVID-19: el que presentó al coronavirus como un enemigo malvado que es una amenaza para la humanidad y que, por lo tanto, debe ser combatido. El artículo organiza el estudio de un conjunto de representaciones del coronavirus en tres niveles -icónico, axiológico y narrativo-y discute cómo la construcción discursiva de un enemigo involucra siempre una serie de mecanismos de naturaleza semiótica que, además de representarlo, contribuyen a su construcción social.

Palabras clave: coronavirus; COVID-19; semiótica; representación; constructivismo.

\begin{abstract}
During the first half of 2020, the novel coronavirus -a biological entity invisible to the human eye-was represented in multiple images, audiovisual products, descriptions, narratives and other modes of visual and verbal articulation. Many of these were developed by international organizations, governments and media outlets, amongst other social actors, with the aim of rendering the threat posed by the virus more tangible. At the same time, these representations also helped shape how people made sense of it in cognitive and emotional terms. Assuming that social reality is constructed in multiple and dynamic processes and interactions that imply the production, distribution and consumption of meaning at various levels, this article examines from a semiotic perspective one of the modes of representations of the coronavirus during the COVID-19 pandemic: the one grounded on the overarching narrative that depicted the virus as an evil enemy that poses a threat to humanity and that, consequently, needs to be fought. The article organizes the study of a number of representations of the coronavirus in three levels - the iconic, the axiological and the narrativeand discusses how the discursive construction of an enemy involves a series of mechanisms ofsemiotic nature that, besides somehow representing it, also shape its social construction.
\end{abstract}

Keywords: coronavirus; COVID-19; semiotics; representation; constructivism.

Nota: Este artículo fue publicado originalmente en el año 2020, en inglés, con el título "From a Biological Entity to a Social Monster. A Semiotic Construction of the Coronavirus During the Covid-19 Pandemic", en la revista italiana Fuori Luogo, 7(1), pp. 105-115. D0I https:// doi.org/10.6092/2723-9608/7041. La traducción del inglés al español -que no presenta cambios respecto a la versión original, salvo por la incorporación de nuevas entradas bibliográficas- fue realizada por su autor. 


\section{Introducción}

En la primera mitad de 2020, la propagación descontrolada del denominado 'nuevo coronavirus' tuvo un fuerte impacto en los dominios sanitario, económico y político de muchos países a lo largo y ancho del mundo. $\mathrm{Al}$ mismo tiempo, esta propagación fue la fuente de una serie interesante de fenómenos discursivos, como, por ejemplo, el surgimiento de narrativas específicas para atribuir sentido a la crisis sanitaria, a las medidas de confinamiento y a la 'nueva normalidad'; la construcción de actores colectivos como 'los trabajadores sanitarios' y 'los más vulnerables' ("Heroes of the Front Lines", 2020); la proliferación de eslóganes positivos como 'andrà tutto bene' (en Italia); la articulación de unas dinámicas específicas de atribución de culpa, estructuradas en la forma de historias causales (Moreno Barreneche, 2020a) y el establecimiento de prácticas simbólicas como las rondas diarias de aplausos en reconocimiento de los esfuerzos hechos por 'los trabajadores sanitarios'. Dada su naturaleza discursiva, estos fenómenos son un objeto de estudio adecuado para la semiótica, la disciplina que estudia el sentido y la significación. En particular, son relevantes para la semiótica social, la rama de la disciplina general cuyo objetivo consiste en aprehender 'el sentido en acción', esto es, comprender los procesos y las dinámicas mediante los que se construye, mantiene y transforma la realidad social (Verón, 1988; Landowski, 2014; van Leeuwen, 2005).

Para quienes investigan en semiótica, fenómenos como las dinámicas de construcción identitaria que ocurrieron en el marco de la pandemia de COVID-19 son sumamente interesantes, ya que permiten acceder al complejo entramado de creencias, imaginarios y discursos dominantes en una sociedad dada (incluida la sociedad global). A modo de ejemplo, en las narrativas que emergieron a nivel global para atribuir sentido a la pandemia, el actor colectivo de 'los trabajadores sanitarios' desempeñó un papel central: los integrantes de este colectivo fueron presentados como 'héroes' que 'combatieron' y 'arriesgaron sus vidas' al ubicarse en 'la primera línea de batalla' para proteger a la humanidad del virus (Moreno Barreneche, 2021). Por otra parte, los actores colectivos de 'los más vulnerables' y 'los irresponsables' -esto es, aquellos individuos que no respetaban las medidas de confinamiento porque no creían o bien en la existencia del virus, o bien en sus efectos perjudiciales para la salud humana ("'If I get corona", 2020) - también cumplieron un rol central en las articulaciones discursivas motivadas por la pandemia. Finalmente, actores colectivos relacionados con nacionalidades específicas, como por ejemplo 'los chinos', fueron con frecuencia utilizados como chivos expiatorios a ser culpados por la catástrofe global. Como se puede apreciar, todas estas son construcciones discursivas que hipersimplifican la realidad social y que no dan cuenta ni de la heterogeneidad ni de la diversidad que se puede encontrar dentro de una sociedad o un grupo dado: en cada uno de los casos mencionados, una serie de grupos de personas imaginados como unitarios fueron posicionados como actores con roles específicos en una articulación narrativa para atribuir sentido a la pandemia.

Además de esta construcción de actores colectivos de naturaleza humana, la pandemia del COVID-19 dio también pie a la construcción discursiva del virus en sí mismo. Si se acepta la distinción analítica entre el reino natural y la cultura (Descola, 2005; Koschorke, 2009), es evidente que, más allá del acto humano de su identificación ("hay un nuevo virus, distinto de otros, con tal y tal propiedades y tal y tal efectos en la salud humana") y de darles un nombre ("este virus se llamará X"), los virus, las bacterias y otros microorganismos pertenecen al reino natural, esto es, un dominio que existe y que funciona independientemente de la intervención humana. A pesar de esta naturaleza no-cultural, durante la pandemia, una serie de procedimientos de naturaleza semiótica ayudaron a 'culturalizar' al coronavirus, ya que dieron forma a cómo actores sociales, tanto individuales como colectivos, percibieron y atribuyeron sentido a esta entidad biológica. Como resultado, en las numerosas narrativas que circularon durante la primera mitad del año 2020, 
al virus constantemente se le 'dio vida' en cuanto que actor central con un rol fundamental en la pandemia, lo que habilitó una explicación causal para dar cuenta de la 'nueva' situación causada por la pandemia.

Este proceso, que sucedió a través de numerosas representaciones de naturaleza discursiva, narrativa y (audio)visual, supuso un desafío desde el punto de vista de la enunciación. Dada su constitución fisiológica, los virus y otras entidades biológicas similares son invisibles al ojo humano, lo que dificulta que los individuos puedan hacerse de una idea clara respecto a cómo se ven estas entidades $\mathrm{y}$, así, a qué son. Como los virus no pueden ser percibidos - a través de la vista, del oído, el tacto, el olfato o el gusto- por los seres humanos de manera directa, ¿cómo pueden estos ganar acceso a esta porción de la realidad con el fin de atribuirle sentido?

Este artículo busca analizar desde una perspectiva semiótica cómo el 'nuevo coronavirus' fue representado $\mathrm{y}$, especialmente, cómo se le 'dio vida' mediante el empleo de unas articulaciones discursivas que involucraron la manipulación de recursos semióticos y que lo presentaron como algo peligroso para el ser humano. Mediante el análisis de tres niveles de la construcción discursiva del coronavirus -el icónico, el axiológico y el narrativo-, el artículo mapea cómo fue representado el virus mediante el uso de metáforas, marcos interpretativos [frames] y connotaciones culturalmente valorizados de manera negativa, como el ser peligroso, malvado, feo, un enemigo, una amenaza, un monstruo y algo con lo que la humanidad está en guerra. La hipótesis de trabajo es que hubo un modo de representación del virus anclado en este frame específico.

La premisa de lo que sigue se apoya en dos aspectos. Por un lado, el constructivismo social, esto es, el enfoque dentro de las ciencias sociales que propone que la realidad es en gran medida socialmente construida mediante procesos intersubjetivos de interpretación y de negociación de sentido (Berger y Luckmann, 1966; Onuf, 1989; Searle, 1995; Verón, 1981). Por el otro, la semiótica, es decir, la disciplina que se encarga de estudiar el sentido y la significación. La combinación de estos dos marcos teóricos, intimamente ligados en el proyecto teórico de la sociosemiótica (o semiótica social), constituye el punto de partida del estudio sobre cómo fue representado -o, mejor, socialmente construido- el coronavirus durante la pandemia en cuanto que enemigo. Además, se presenta un análisis más general sobre cómo la categoría del ‘enemigo' parece necesitar una existencia tangible para poder ser debidamente temido, por lo que el enemigo suele ser representado a través de imágenes, descripciones y otros artificios semióticos que reflejan una clara axiología. Así, más allá de referir de algún modo a una realidad objetiva - un virus que es peligroso para la salud humana-, estas representaciones construyen, a su vez, al virus como un enemigo.

\section{La semiótica y la construcción social de la realidad}

El objetivo de esta sección es presentar de manera general la semiótica y sus desarrollos más recientes. Especificamente, se presenta el enfoque constructivista al que suscriben los investigadores interesados en el estudio de la realidad social, junto con una de las hipótesis centrales de la semiótica cognitiva: aquella según la cual la percepción humana $-\mathrm{y}$, con ella, la cognición- se articula en términos narrativos (Paolucci, 2012). De forma resumida, para los semiotistas la realidad social es el resultado de complejos y heterogéneos procesos de significación y atribución de sentido que son intersubjetivos, es decir, implican intercambios, acuerdos y negociación de sentido entre actores sociales, tanto individuales como colectivos.

El estatus actual de la semiótica como disciplina relativamente autónoma es el resultado de una serie de desarrollos teóricos del siglo XX. Con todo, a comienzos de la tercera década del siglo XXI, todavía no hay consenso entre sus practicantes respecto al alcance, el propósito y el método de la investigación semiótica: por un lado, mientras que algunos sostienen que debería tratarse de una disciplina descriptiva con carácter científico, otros 
defienden su finalidad crítica y deconstructiva (Bitonte, 2008; Demaria, 2019; Landowski, 2019); por otro lado, mientras que algunos consideran que su foco debería estar puesto en el estudio y análisis de sistemas de signos y de las estructuras que estos forman, otros defienden un análisis de corte más dinámico de los procesos de atribución de sentido (Landowski, 2014; Verón, 1988; van Leeuwen, 2005). Las tareas de discutir la naturaleza de la semiótica como proyecto teórico, así como de mapear las múltiples tradiciones y escuelas que actualmente coexisten en este campo (Traini, 2006; Violi, 2017) quedan por fuera del alcance de este artículo. Para abarcar dichas tradiciones de manera más o menos justa, se podría definir a la semiótica de manera general como la disciplina -o la mirada- dentro de las ciencias sociales interesada por la significación y la atribución de sentido, un proyecto que, ciertamente, no se limita al estudio de signos y de sistemas de signos, tal como suele ser caracterizada (Eco, 2000; Fabbri, 1998; Hénault, 2012; van Leeuwen, 2005).

Dentro de esta definición general, la semiótica social puede concebirse como la rama de la disciplina enfocada en la producción, la circulación y el consumo de sentido en el marco de la vida social. Se trata, por lo tanto, de una disciplina con un anclaje empírico y con un alcance interdisciplinario: como sostiene Van Leeuwen (2005, p. 1), la práctica sociosemiótica "requiere sumergirse no solo en conceptos y métodos semióticos, sino también en algún otro campo". Es por eso que, de manera frecuente, los intereses y los objetos de estudio de la semiótica social son cercanos a los de la antropología (Landowski, 2016a; Geertz, 1973) y de la teoría social (Van Leeuwen, 2005). Esto es así porque el alcance de la disciplina se apoya tanto en el tratamiento de artefactos de naturaleza tangible, como los productos y objetos culturales, como también de fenómenos de naturaleza más intangible, como las prácticas (Fontanille, 2008; Demuru, 2017), las interacciones (Landowski, 1997; 2014; 2016b) y las 'formas de vida' (Fontanille, 2015a; 2015b).

La sociosemiótica es, entonces, la rama de la semiótica que se interesa por aprehender el sentido en acción, situado, in vivo, es decir, localizado en las interacciones y las prácticas que constituyen la realidad social (Landowski, 1997; 2014) como, por ejemplo, las representaciones y los imaginarios sociales relacionados a la pandemia del COVID-19. Si bien refieren a un fenómeno natural, estas representaciones fueron importantes para la construcción de la pandemia como una situación con sentido. La idea general subyacente a la investigación semiótica es que, a través del estudio de productos culturales específicos como imágenes, textos, objetos, prácticas, interacciones, etc., es posible acceder a los procesos productivos y a las ideologías que los hacen posibles (Verón, 1988). En otras palabras: mediante el examen del plano de la expresión -textos, articulaciones figurativas, objetos semióticos, etc.-, los investigadores pueden acceder al plano del contenido, en el que se encuentran las estructuras profundas que hacen posible la significación. Es por eso que, en cuanto que proyecto interesado en el estudio de la realidad social, la sociosemiótica se funda en una premisa constructivista, según la cual la realidad no es ni dada ni pre-social, sino que es construida tanto en numerosas interacciones que ocurren en diversos contextos, como en y por los medios de comunicación (Landowski, 2014; Verón, 1981).

De este modo, los imaginarios sociales, los discursos hegemónicos, las narrativas emergentes y las formas de representación en general que han sido utilizadas durante la pandemia de COVID-19 para darle un sentido tanto al coronavirus como a los cambios ocurridos desde febrero de 2020 en el ámbito de la vida cotidiana, constituyen un objeto de estudio de sumo interés para la sociosemiótica. A la luz de los objetivos planteados para este artículo, al examinar representaciones específicas del coronavirus se gana acceso a las fuerzas discursivas e imaginarias subyacentes, esto es, aquellas que hacen de estas representaciones no solo posibles, sino también que tengan un sentido. Como propone Van Leeuwen (2005, p. 26), "estudiar cómo las cosas llegan a ser lo que son [come into being] es la llave para comprender por qué son lo que son”. En este sentido, incluso si el coronavirus 
es una entidad con una existencia independiente de la acción humana, lo que las sociedades entienden sobre el coronavirus, así como los modos en que le atribuyen sentido a esta porción de la realidad natural, está cargado de discursos, representaciones y connotaciones que son producto tanto de acontecimientos históricos contingentes como de aspectos culturales. Como fue mencionado, todos estos elementos tienen un impacto sustantivo en las dimensiones tanto cognitiva y afectiva y tanto a nivel individual como colectivo. En síntesis, esto da cuenta de cómo la cognición y la percepción del reino natural están fuertemente mediadas $-\mathrm{y}$, por consiguiente, moldeadaspor elementos culturales de naturaleza discursiva. En la era de las redes sociales digitales, este principio llega a su extremo: las creencias sobre el virus, la pandemia y cómo comportarse están fuertemente mediadas y moldeadas por imágenes, descripciones, narrativas, marcos interpretativos y otras representaciones que, sin ningún tipo de control, circulan en estas plataformas digitales.

La idea de que la percepción está mediada por códigos culturales es particularmente interesante para la semiótica cognitiva, esto es, la rama de la disciplina que se ocupa de estudiar la atribución de sentido en términos cognitivos (Paolucci, 2012; 2020). Un principio central de este campo de investigación es el 'principio de narratividad', al que se concibe como "una forma profunda que se puede encontrar en todos los discursos" (Paolucci, 2012, p. 299) y que tiene una influencia importante en la estructuración del pensamiento. Según esta hipótesis, el pensamiento solamente puede volverse algo con sentido a través de una configuración narrativa de los eventos. Esta idea, que se apoya en una serie de principios bien conocidos en el campo de los estudios narrativos, implica que la identificación de distintos actores, imaginados como involucrados en una trama determinada, se vuelve una pieza central para que el sentido pueda existir. $\mathrm{Al}$ mismo tiempo, esta mediación narrativa de la percepción construye la realidad social percibida como una con sentido. En lo que respecta al objeto de estudio de este artículo -la representación del coronavirus como un monstruo malvado que es un enemigo de la humanidad-, el foco está puesto en cómo el virus ha sido representado: no como una entidad biológica invisible, sino como un personaje específico, con un rol específico, que forma parte de una historia específica.

\section{De entidad biológica a monstruo malvado: dándole vida al coronavirus}

Luego de haber delimitado en la sección precedente el alcance del artículo, se procede ahora a la identificación de los mecanismos y recursos semióticos a través de los cuales, durante la pandemia de COVID-19, se le ha dado vida al coronavirus como un personaje malvado. El corpus empleado para el análisis está conformado por múltiples creaciones que, durante la primera mitad de 2020, circularon tanto en distintos paisajes mediáticos -particularmente en las redes sociales digitales, aunque no exclusivamente- así como offline. Estas creaciones son el resultado de procesos activos de enunciación por parte de instituciones gubernamentales, organismos internacionales, instituciones científicas y usuarios particulares (como diseñadores gráficos e influencers). Todas estas representaciones fueron creadas por alguien (puede tratarse de un enunciador tanto individual como colectivo) siguiendo unos códigos específicos, lo que permitió que estos productos semióticos pudiesen ser interpretados como unos que referían al coronavirus.

Antes de comenzar el análisis, parece importante pensar cómo se podría representar un virus en el contexto de una pandemia global. Una de las respuestas posibles a la pregunta sobre cómo los seres humanos podrian tener un acceso cognitivo al virus - esto es, una porción del mundo natural que no es perceptible de manera directa- se apoya en el uso de tecnologías como el microscopio. Esta herramienta, extiende el alcance de la percepción humana porque supone una superación de sus limitaciones naturales y permite a los observadores ver al virus directamente (aunque esta visión solo sea posible mediante el uso de un dispositivo). Las imágenes 
resultantes del uso de un microscopio constituyen un primer conjunto de representaciones del virus que, de algún modo, le 'dan vida', ya que lo vuelven visible a los ojos humanos. Por otro lado, otro modo de atribuir sentido a un virus y a los peligros que puede representar consistiría en el uso de descripciones sobre su constitución genética, sus dinámicas reproductivas y/o sus efectos en la salud humana, en el ámbito sanitario y en la economía. Estos dos modos de representación -el primero, visual; el segundo, narrativo- comparten una naturaleza científica, es decir: se apoyan en la premisa de que hay algo así como una 'realidad', externa e independiente del lenguaje, pasible de ser representada objetivamente mediante el uso de recursos visuales y lingüísticos que pueden describirla de manera fidedigna mediante el seguimiento de un código de correspondencia, en el que una imagen o una descripción del virus refleja la realidad. Como se argumentará al discutir el nivel icónico, dado que este tipo de representación es un estándar en el campo de la comunicación de la ciencia, fue uno de los modos más comunes de representar al coronavirus.

Sin embargo, como se argumentará más adelante, durante la primera mitad de 2020, al coronavirus también se le dio vida a través de representaciones que trascienden el ámbito de lo científico: numerosas imágenes, descripciones, narrativas y otras articulaciones discursivas fueron desarrolladas por varios enunciadores con el fin de ayudar a que la gente pudiese visualizar la amenaza del coronavirus. Así, durante la pandemia del COVID-19, además de los -necesarios- modos de representación científica, hubo otros modos de construcción social que, a pesar de su carácter no-científico, tuvieron un fuerte impacto en cómo el coronavirus fue (y continúa siendo) percibido tanto a nivel individual como colectivo: a nivel individual, porque estas representaciones tienen un impacto tanto cognitivo como afectivo en cómo la gente le atribuye sentido al virus; a nivel colectivo, porque estas representaciones fueron la base para la justificación narrativa de las medidas políticas tomadas por gobiernos para lidiar con la pandemia.
Para llevar a cabo de manera ordenada el análisis sobre cómo se le dio vida al virus como un enemigo, el estudio que sigue se organiza en tres niveles: (1) el icónico, que se ocupa de analizar cómo fueron creadas imágenes científicas del virus, (2) el axiológico, consistente en representaciones normativas y cargadas de valor, principalmente a través del uso de metáforas y connotaciones que, culturalmente, tienen una carga valorativa negativa, y (3) el narrativo, focalizado en las articulaciones discursivas en forma de historias y marcos interpretativos [frames] utilizados para atribuir sentido al virus en cuanto que amenaza para la humanidad.

\section{Nivel icónico}

El término 'figurativización', que es un término técnico perteneciente a la caja de herramientas de la semiótica, se utiliza para referir a la operación de volver al discurso concreto, tangible y reconocible por los lectores a partir de sus competencias enciclopédicas. Una imagen considerada figurativa se opone a lo abstracto. El punto central de la definición de 'figurativización' de Greimas y Courtès (1979) en su conocido Diccionario es que su característica definitoria consiste en una articulación del plano de la expresión que el lector pueda reconocer como una figura específica. Este reconocimiento se basa en una interpretación que, como toda interpretación, depende de la cultura.

En esta conceptualización, la distinción establecida por Peirce entre íconos, índices y símbolos en cuanto que tres tipos diferentes de signos resulta iluminadora. Estas tres categorías refieren a distintos modos en los que un signo se relaciona con lo que representa. En el caso de las representaciones científicas del mundo natural, de especial relevancia son los íconos, esto es, aquellos signos que tienen algún tipo de parecido [resemblance] con lo que representan. Esto quiere decir que el significante, "en algún aspecto o en algún grado, se ve como el significado, del modo en que la imagen de un árbol se ve como un árbol" (Van Leeuwen, 2005, p. 49). 
De manera similar, Greimas (1984, p. 8) sostiene que los sistemas icónicos de representación son por lo general descritos como "diferentes de otros porque la relación reconocible entre los dos modos de 'realidad' no es arbitraria, sino 'motivada', ya que presupone una cierta identidad, total o parcial, entre los rasgos y las figuras de lo representado y de la representación".

En teoría semiótica, la idea de iconismo ha sido extensamente criticada, principalmente por Umberto Eco (2000). Para evitar la compleja discusión sobre el tipo específico de producción significa involucrado en el iconismo, en estas páginas el término se utilizará para referir a un modo de representación en el que se evidencia algún tipo de vínculo reconocible entre el contenido y la expresión, como suele suceder en representaciones que buscan producir un tipo de conocimiento objetivo del mundo natural.

¿Cómo se representó al coronavirus mediante imaginería visual de naturaleza icónica? ¿Cuáles fueron los pasos de esta operación semiótica? El primer paso consiste en identificar y segmentar la realidad según parámetros que son arbitrarios: la comunidad científica identificó un virus con propiedades particulares que lo hicieron un buen candidato para un nombre ‘propio' que permitiese su distinción de otros virus (en particular, de otros tipos de coronavirus).

Luego, para concientizar al público general sobre la especificidad de esta variedad particular del coronavirus y sus peligros, se desarrollaron materiales de comunicación como imágenes, folletos y animaciones audiovisuales.

En este sistema general de comunicación, el hecho de que el coronavirus sea una entidad invisible al ojo humano significó un desafío importante. Por lo tanto, el primer paso consistió en darle al coronavirus algún tipo de anclaje o configuración material (Bitonte, 2008), es decir, en volverlo visible y reconocible de algún modo. El punto de partida para llevar a cabo esta tarea consistió en examinar al virus a través del microscopio (Figura 1).

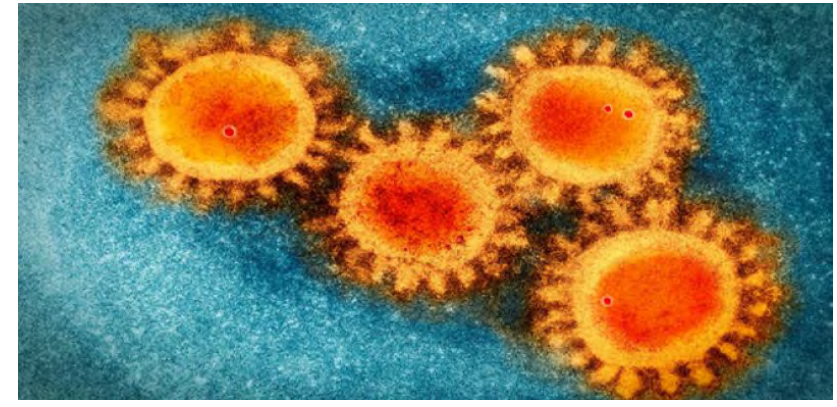

Figura 1. Imagen microscópica del coronavirus. Fuente: The European Research Council Magazine (2020)

Imágenes como la de la Figura 1 constituyen un primer tipo de representación visual del coronavirus como entidad diferenciada de otras. Si bien las imágenes de este tipo pueden diferir en tamaño, color y definición, la forma de las células representadas permanece inalterada. Es precisamente de este elemento de donde proviene el nombre del tipo de virus: el uso del prefijo 'corona-' es el resultado de una traducción en el ámbito lingüístico (una palabra) de un rasgo perteneciente al ámbito topológico (una forma). Si hay algo que inmediatamente ayuda a un observador a atribuir sentido a una imagen como una que representa al coronavirus es precisamente su forma. Este principio es el que subyace también a las creaciones visuales de las Figuras 2, 3 y 4, en las que, a partir de un anclaje en este aspecto topológico que da una identidad diferencial al virus, el modo de representarlo consiste en un círculo con pinchos a su alrededor.

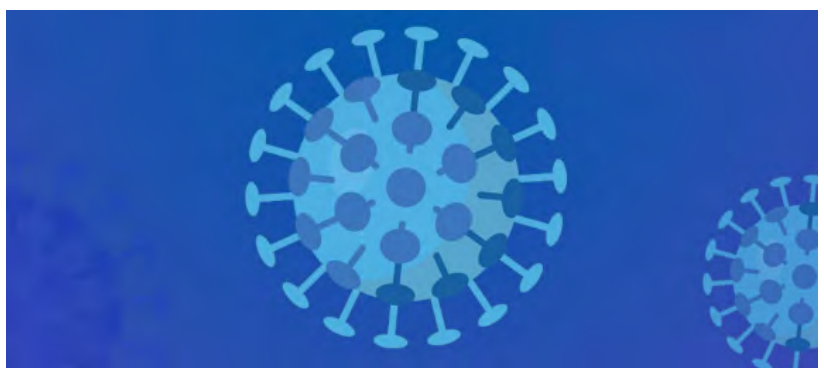

Figura 2. Representación icónica del coronavirus utilizada por la Comisión Europa en su sitio web. Fuente: European Comission (2020). 


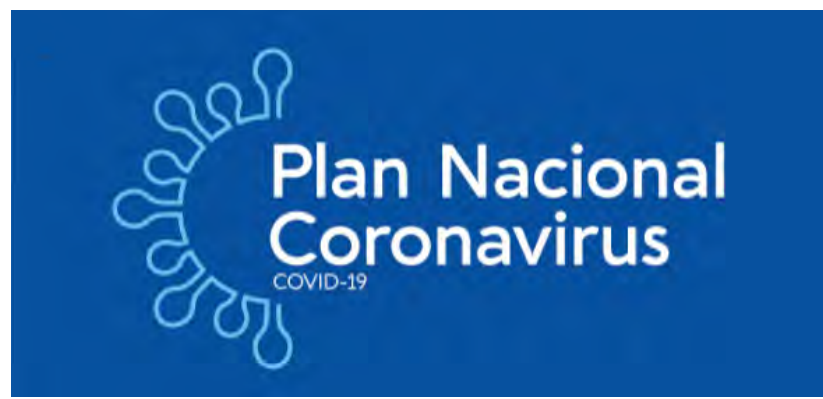

Figura 3. Logo creado por el Ministerio de Salud Pública de Uruguay para identificar su plan contra la propagación del coronavirus. Fuente: Ministerio de Salud Pública (2020).

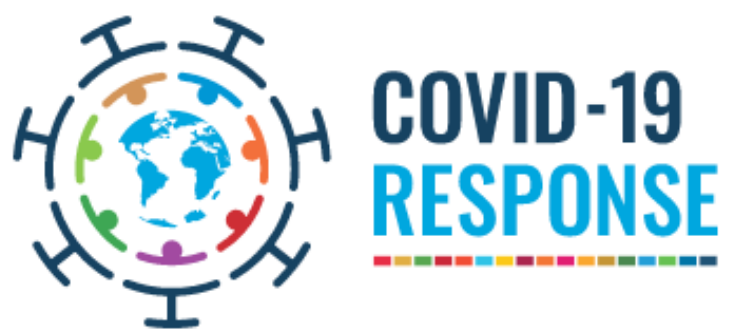

Figura 4. Logo creado por la ONU para identificar a la respuesta global al COVID-19. Fuente: Naciones Unidas (2020).

La Figura 2 es una imagen, de naturaleza claramente icónica, utilizada por la Comisión Europea en su sitio web. La Figura 3 es el logotipo creado por el Ministerio de Salud Pública de Uruguay para identificar su Plan Nacional para lidiar con la pandemia. En el logo, la referencia al virus figura mediante el uso de un trazo que copia su forma tal como es vista a través del microscopio. La Figura 4 es el logotipo creado por la ONU para identificar su repuesta global a la pandemia, un objetivo que parece ser lo que motivó la inclusión de un mapa del mundo en el centro del círculo. Incluso si cada una de estas tres imágenes tiene una identidad específica (lo que las diferencia de otras representaciones), todas se basan en un principio de similitud entre los diseños visuales y la forma 'real' del virus, según lo que se puede ver a través del microscopio. En este mecanismo se puede identificar claramente el modo icónico de representación: se evidencian unas imágenes mentales, moldeadas culturalmente, respecto a cómo luce el coronavirus, que sirven como referencia para la creación de elementos de diseño gráfico como, por ejemplo, logotipos.

Dentro del ámbito de las representaciones icónicas de naturaleza científica, si ha habido una representación del virus que, en parte debido a su vasta circulación en redes sociales digitales, se volvió un ícono de la pandemia, es la creada por Allisa Eckert, una dibujante médica en el Centro de Control y Prevención de Enfermedades (CDC) de los Estados Unidos (Figura 5), en enero de 2020.

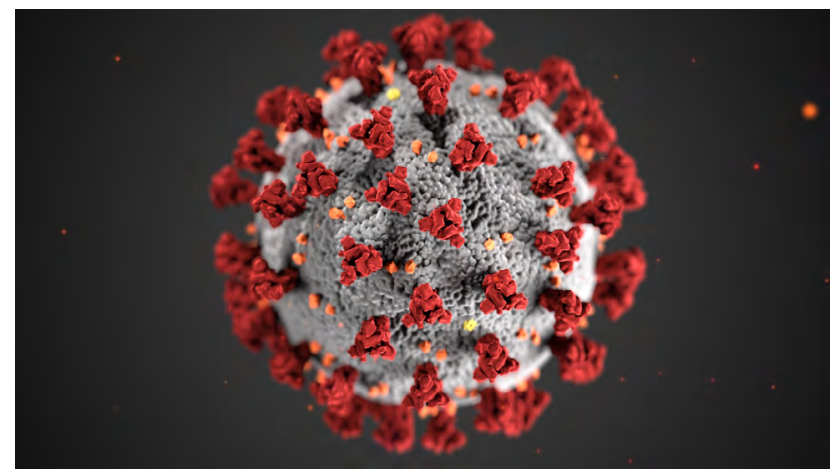

Figura 5. Representación visual del coronavirus creada por el CDC de los Estados Unidos. Tomado de Giaimo (2020).

Como respuesta al encargo de proponer "una identidad" para el virus, Eckert y su equipo diseñaron esta conocida imagen en 3D (Giaimo, 2020; Talbot, 2020), que constituye un típico ejemplo de lo que se denomina 'visualizaciones científicas' [science visualizations] (Homer y Plass, 2009), esto es, representaciones visuales que tienen un valor científico y que, por eso, deben 'reflejar' la realidad lo más fidedignamente posible, ya que su fin comunicacional en cuanto que creación semiótica consiste en vehiculizar un sentido de tipo científico. Al tratar con este tipo de representaciones de los virus, los diseñadores técnicos pueden proceder de distintas maneras: mientras que una opción sería enfocarse en sus vectores - esto fue lo que hizo el 
equipo de Eckert cuando se le solicitó darle vida al virus del zika (el foco estuvo puesto en el mosquito)-, otra podría ser enfocarse en los síntomas de la enfermedad, tal como el CDC hizo al representar al virus del ébola. Esto muestra cómo es que a los virus y a otras entidades biológicas se les puede 'dar vida' de distintas maneras, mismo dentro del ámbito de las representaciones de tipo científico.

Para la sociosemiótica, de especial interés son los mecanismos mediante los cuales el coronavirus fue representado y, así, construido como un objeto diferencial, con un nombre y que es (o que, idealmente, debería ser) algo con sentido para la gente. En este proceso, los mecanismos atribuidos al tipo icónico de representación son claramente visibles, ya que la forma que cualquier persona utilizaría actualmente al solicitársele que dibuje al coronavirus - por ejemplo, en un juego como el Pictionary - tendría un evidente parecido natural con el virus tal cual es (al menos, tal como es visto a través de la lente del microscopio). Este tipo de imagen, de naturaleza y valor puramente científicos, se ha convertido en la base para otros modos de representación y, así, ha dado pie a diferentes maneras de dar al virus una forma y, con ella, una identidad delimitada. La idea de una 'parecido físico' que se encuentra en el corazón mismo del modo icónico de representación parecería ser central en este caso particular.

\section{Nivel axiológico}

La hipótesis de este artículo es que uno de los modos en que el coronavirus fue representado consistió en presentarlo como un monstruo malvado. Este tipo de representación, que se ubica por fuera del ámbito de las representaciones científicas y que conlleva una clara axiología, contribuyó a la percepción general del virus como un enemigo y, por lo tanto, como una amenaza. En semiótica, la axiologización se define como un proceso en el que se atribuye a una porción del discurso un valor positivo o negativo (Hénault, 2012; Greimas y Courtès, 1979). En historias ficcionales, los personajes no solamente son descritos objetivamente, sino que son también 'marcados' con adjetivos, descripciones de naturaleza valorativa y otras marcas connotativas, que ayudan al lector a ubicarlos en un eje que oscila entre las categorias de ‘bueno' y ‘malo'. No es casualidad que las brujas sean usualmente representadas vistiendo ropa vieja y con características físicas que culturalmente se relacionan con la fealdad.

El coronavirus no fue una excepción a este mecanismo semiótico: se le atribuyó un claro valor negativo, derivado de sus efectos nocivos en la salud humana. Si bien el virus podría haber sido representado, por ejemplo, como una 'simpática' e 'inocente' entidad que está 'perdida' en 'el mundo de los humanos', una representación de este tipo no habría contribuido al objetivo general de comunicación de la estrategia de información de salud pública, consistente en crear un imaginario social específico respecto a los peligros asociados al virus. Un objetivo de este tipo requiere que la gente tenga miedo de las consecuencias del virus y, así, del virus en sí mismo. Esto significa que, desde un punto de vista semiótico, una axiología negativa debe ser empleada en las representaciones.

Esta axiologización negativa se puede apreciar claramente en múltiples representaciones como dibujos, animaciones, caricaturas y comics, en los que el virus es representado con rasgos humanos como, por ejemplo, un rostro (Figuras 6, 7 y 8).

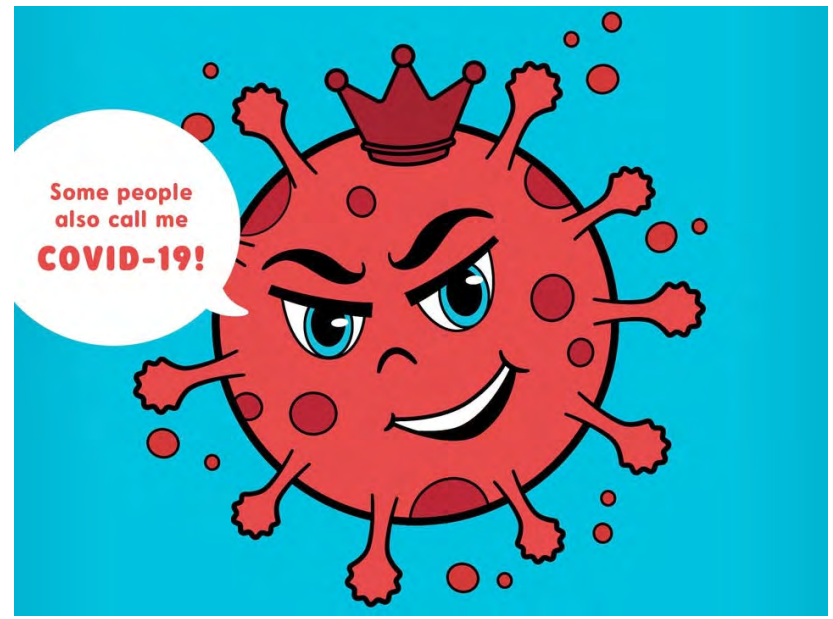

Figura 6. Representación visual del coronavirus, I. Tomado de Forster (2020). 


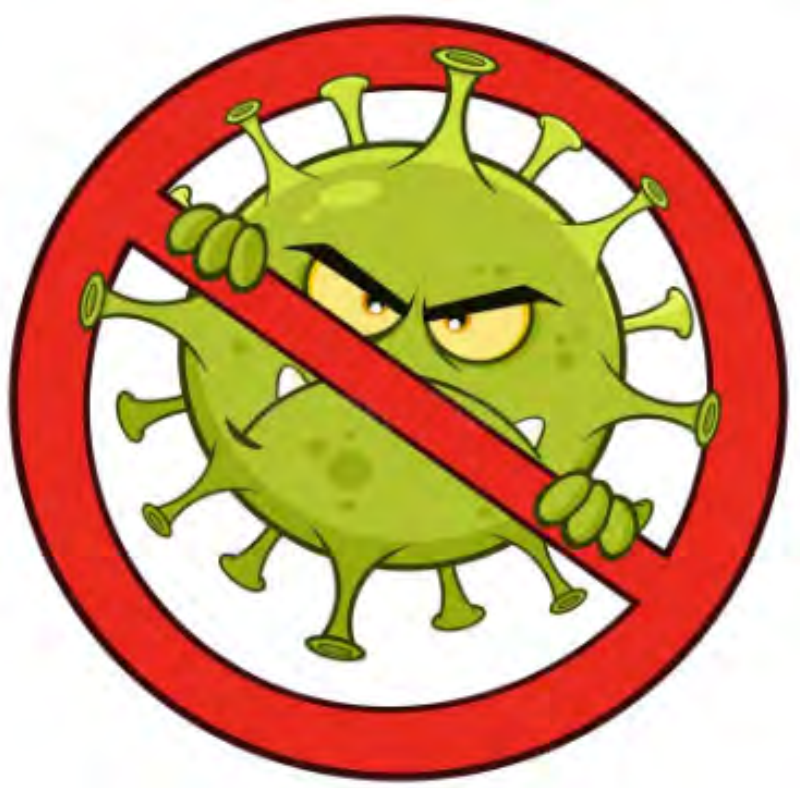

Figura 7. Representación visual del coronavirus, II. Fuente: "Evil Coronavirus" (2020).

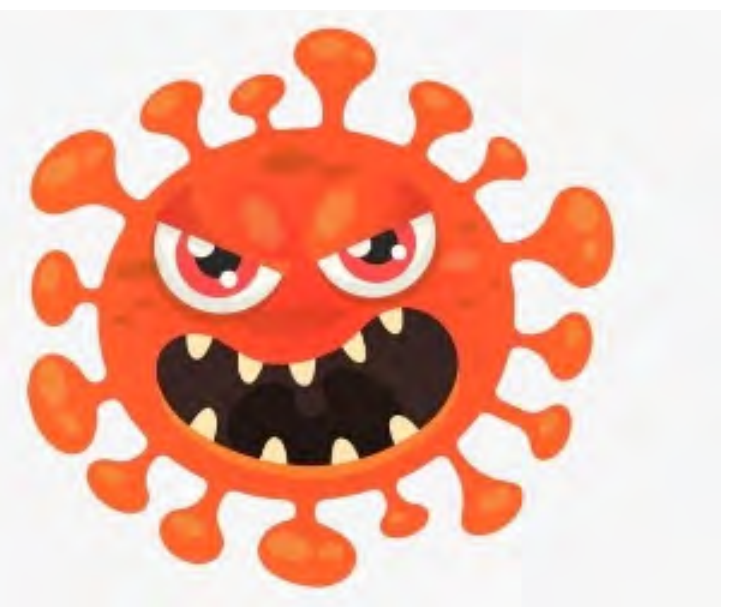

Figura 8. Representación del coronavirus, III. Tomado de "Free-Lanced in lockdown" (2020).
En estas imágenes, a las que el lector seguramente podrá agregar muchas más que, de algún modo, son equivalentes dado que expresan el mismo contenido, se evidencia una serie de aspectos interesantes.

En primer lugar, se trata de representaciones en las que el objetivo de la producción semiótica claramente trasciende una mera representación científica, ya que parecería haber una intención comunicativa subyacente que es menos neutral. En segundo lugar, en cada uno de los casos, el coronavirus ha mantenido su forma como rasgo distintivo, lo que resulta un elemento fundamental para su reconocimiento e identificación por parte del lector (en la Figura 6, como recurso isotópico que refuerza su nombre, el virus también lleva una corona).

Finalmente, el virus ha sido representado con signos visuales que no cuadran con su naturaleza y que, de algún modo, activan significados vinculados con el lado 'malo' del continuum antes mencionado, como el ceño fruncido -recurso normalmente utilizado para representar a los villanos en los dibujos y en las películas animadas-y la boca en una posición que sugiere una sonrisa maliciosa (Figura 6), enojo (Figura 7) o una disposición a morder (Figura 8).

Signos como estos, que activan inmediatamente una capa emocional de interpretación que trasciende las meras funciones de reconocimiento e identificación, le otorgan al coronavirus - una entidad biológica desprovista de emociones y de intenciones moralesunos rasgos humanos fácilmente reconocibles por los individuos, que los ayudan a percibirlo de manera axiologizada.

Otro ejemplo interesante de este modo de representación, en este caso perteneciente al mundo offline y valioso en cuanto que evidencia que la representación del virus no es un fenómeno solamente limitado a los ámbitos mediáticos, es la producción de las tradicionales piñatas en América Latina (Figuras 9 y 10). 


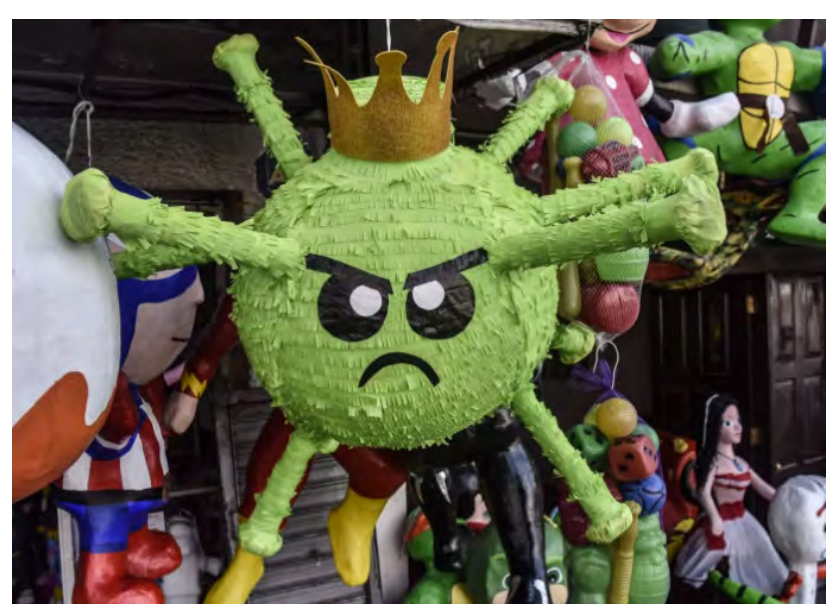

Figura 9. Piñata con la forma del coronavirus, I. Fuente: Jasso (2020).

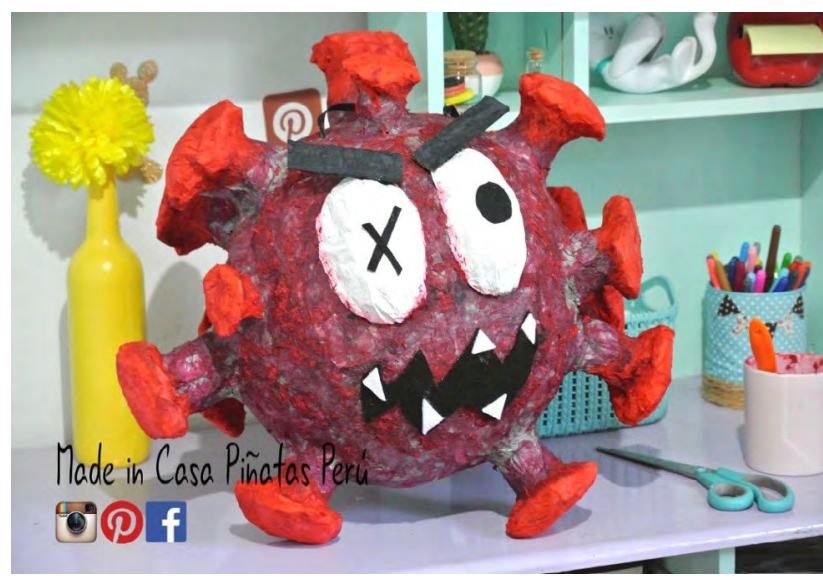

Figura 10. Piñata con la forma del coronavirus, II. Fuente: Made in Casa Piñatas Perú (2020).

Al igual que en el caso de los dibujos de las Figuras 6, 7 y 8 , las piñatas (Figuras 9 y 10) también fueron diseñadas con caras poco amistosas, creadas a través del recurso a unos códigos convencionales fácilmente reconocibles como opuestos a lo 'bueno': una sonrisa invertida, dientes afilados y las cejas en una posición que genera la idea de enojo. En todas estas representaciones, la lógica parecería ser la siguiente: dado que el coronavirus es peligroso para los seres humanos, es malo y, por lo tanto, debe ser representado como una criatura fea. En esta dinámica hay involucradas dos operaciones de naturaleza semiótica: por un lado, la creación de representaciones basada en un eje moral que oscila entre lo 'bueno' y lo 'malo', en el que se ubica al coronavirus en el segundo polo; por el otro, una asociación implícita entre lo malo y lo feo.

Esta segunda operación se relaciona con las reflexiones de Umberto Eco sobre la construcción del enemigo, en las que identifica la asociación entre lo malo y lo feo como uno de los mecanismos constitutivos de dicho proceso. Según Eco (2011, p. 18),

El enemigo debe ser feo porque se identifica lo bello con lo bueno (kalokagathia), y una de las características fundamentales de la belleza ha sido siempre lo que la Edad Media denominará integritas (es decir, tener todo lo que se requiere para ser un representante medio de una especie, por lo cual, entre los humanos, serán feos los que carecen de un miembro, de un ojo, tienen una estatura inferior a la media o un color «deshumano»).

Este vínculo entre el enemigo y la fealdad es evidente en el caso de las representaciones axiologizadas y no-cientificas del coronavirus, las que, sin dudas, han jugado un papel importante en cómo el virus ha sido imaginado tanto por individuos como por sociedades. Como se puede apreciar, estas representaciones incluyen criaturas que podrían ser identificadas como monstruos, una categoría de sentido ya conocida por las audiencias y que, a pesar de las evidentes diferencias culturales que se evidencian entre representaciones mentales e imaginarios de este tipo, los ayudan a atribuir sentido a la nueva amenaza. En este sentido, las cinco imágenes analizadas en esta sección podrían, por ejemplo, ser fácilmente confundidas con pokemones por alguien que no esté familiarizado con los personajes de esta franquicia. Representaciones del coronavirus como un monstruo, un alienígena y otras criaturas malvadas, enojadas, feas y no humanas también fueron utilizadas en contextos mediáticos 
audiovisuales, como noticieros (Andacht, 2020) y la prensa ("The aliens among us", 2020). Pero también pueden encontrarse en expresiones creativas como la que se muestra en la Figura 11. El hecho de que dicho dibujo haya sido creado por un niño parecería confirmar la hipótesis de una percepción de lo desconocido que está mediada por las categorías ya conocidas, como la de monstruo.

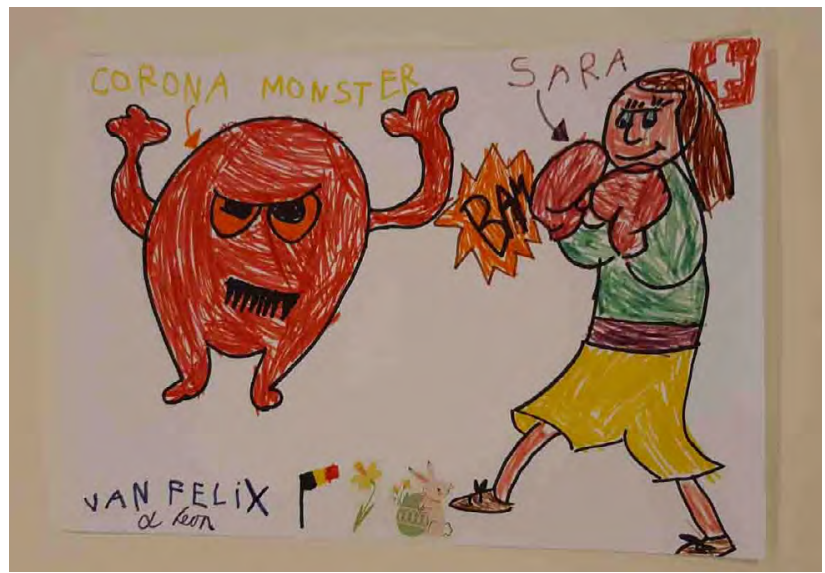

Figura 11. Dibujo del coronavirus compartido por Sara Rollof. Fuente: House of European History (2020).

\section{Nivel narrativo}

Finalmente, otro modo en el que se le dio vida al coronavirus en 2020 fue mediante el uso de descripciones y narrativas de naturaleza metafórica en las que este desempeñaba un rol específico. En la Figura 11, por ejemplo, además de la representación del coronavirus como un monstruo, hay también un framing narrativo apoyado en la idea de un combate, una metáfora frecuentemente utilizada en la vida cotidiana para referir a cómo un individuo lidia con una enfermedad. Según Lakoff y Johnson (1986, p. 255), las metáforas son "uno de los mecanismos más básicos que poseemos para entender nuestras experiencias". Es decir: estas tienen un valor cognitivo, ya que ayudan a abordar fenómenos a través del conocimiento existente a partir de una transferencia de significado.
Una de las metáforas utilizadas para atribuir sentido a la pandemia de COVID-19 fue la idea de que el virus es un enemigo con quien la humanidad está en guerra (Battistelli, 2020; Cassandro, 2020). Como ya se mencionó, no hubo narrativas que representaran al virus como una inocente y/o amistosa entidad parasitaria que lucha por su vida y que, para eso, necesita al sistema humano, para reproducirse a sí misma y para alcanzar un 'final feliz'. En la narrativa hegemónica, se lo ha representado como una suerte de 'invasor no deseado' - una dinámica similar a la trama de la película Alien, de Ridley Scott (Andacht, 2020) - que la humanidad, representada como un actor colectivo, homogéneo y unitario, debe combatir y vencer. A modo de ejemplo, el comic uruguayo Coco y Fran contra el coronavirus, creado por Nicolás Peruzzo y Alejandro Rodríguez Juele (2020) y dirigido a un público infantil, cuenta la historia del intento por parte del coronavirus de invadir el reino humano. Metáforas e imágenes relacionadas con invasiones y con la guerra conducen a la emergencia de otras representaciones relacionadas, como la idea de 'héroes' que 'luchan contra el enemigo' en 'la primera linea de batalla' ("Heroes of the Front Lines", 2020; Moreno Barreneche, 2021). Pero esta guerra no es una guerra estándar, contra otros humanos: es contra una criatura monstruosa, fea y malvada.

Algunos estudios muestran que el uso de metáforas militares para atribuir sentido a las enfermedades puede tener efectos indeseados (Hauser y Schwarz, 2019; Sontag, 1978). En un artículo que discute si es apropiado utilizar la metáfora de la guerra para tribuir sentido a la pandemia, Testa (2020) subraya la necesidad de ser cautelosos al escoger las palabras para referir a las cosas. Para Testa, cuando el entonces presidente de los Estados Unidos, Donald Trump, deliberadamente eligió utilizar la expresión 'virus Chino' en lugar de 'coronavirus', tomó una decisión respecto a cómo el virus sería percibido por la audiencia a la que se estaba dirigiendo. Operaciones semióticas de este tipo tienen el poder de moldear el sentido que es atribuido a las cosas, a los eventos y a otros fenómenos por parte de la gente. Como sostiene 
Van Leeuwen (2005, p. 32), "toda metáfora tiende a destacar algunos aspectos de su dominio de aplicación y a ocultar otros”. Para Testa (2020), el uso de la metáfora de la guerra tiene connotaciones vinculadas con significados que no están alineados con una pandemia: mientras que la esencia de la guerra se estructura en torno al concepto de división, la de una pandemia se estructura -0, al menos, debería estructurarse- en torno a la idea de solidaridad. Además, Testa (2020) sostiene que la pandemia de COVID-19 no fue un caso de guerra, ya que no hubo un enemigo, dado que, en cuanto que entidad biológica parasitaria, "el virus no nos odia. Ni siquiera sabe que existimos. De hecho, no sabe nada ni de nosotros ni de sí mismo". Para la autora, el riesgo de utilizar la metáfora de la guerra radica en que puede fomentar acciones de corte autoritario. Esta precaución parece haber sido identificada también por Eco (2011, p. 35), quien sostiene que "sin el contrapeso de la guerra, un gobierno no podría establecer ni siquiera la esfera de su misma legitimidad".

Dado que el frame de la guerra necesita de la presencia de un enemigo, en la narrativa hegemónica de la pandemia de COVID-19 como una guerra ha habido un proceso de construcción del coronavirus como enemigo. Esto ha ocurrido a través de su identificación como un 'Otro', como un 'no-Nosotros' que es una amenaza. Si las identidades son posicionalidades relacionales, es decir, son construidas mediante el establecimiento de límites y fronteras entre unidades de sentido que son consideradas distintas (Arfuch, 2005; Mouffe, 2007; Moreno Barreneche, 2020b), entonces, en términos narrativos, al coronavirus se le ha dado vida mediante un destaque de los peligros que supone para el bienestar y la normalidad de la humanidad y, a causa de la mediación de la metáfora de la guerra, se lo ha representado como un enemigo al que 'Nosotros, los humanos' combatimos. Como se mencionó, el uso de esta metáfora condujo a otros roles e imágenes como 'el frente de batalla' y 'los héroes', que también pueden verse claramente en creaciones de naturaleza semiótica, como el mural que se ve en la Figura 12.

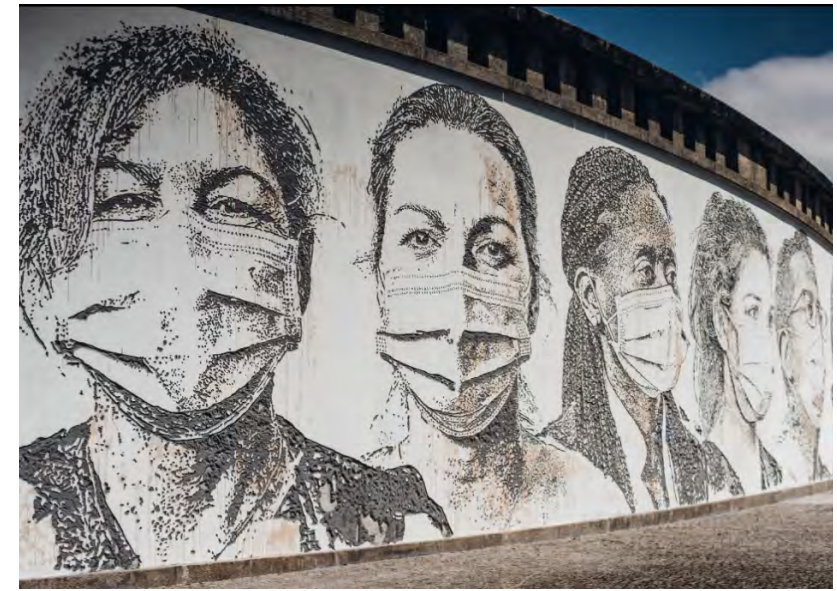

Figura 12. Mural representando a los trabajadores sanitarios en Lisboa, Portugal. Tomado de Pacheco Miranda y Pinto da Costa (2020).

\section{Un abordaje semiótico sobre la construcción discursiva del enemigo}

Según algunos de los principios centrales de los estudios narrativos, toda historia incluye un número de roles estándares, como 'el héroe', 'el villano' y 'el donante' (Propp, 2000). Para los semiotistas interesados en el estudio de la realidad social, de especial interés es el rol del 'enemigo', esto es, un '0tro' que es presentado y representado por oposición a un 'Nosotros' y, por lo tanto, considerado una amenaza.

En un ensayo titulado Construir al enemigo, Umberto Eco rastrea cómo 'el enemigo' ha sido representado en una serie de casos históricos y señala la importancia de la existencia de 'algo' que sea percibido como 'un enemigo' para poder construir la idea misma de un 'Nosotros'. Para Eco (2011, p. 14-15), "tener un enemigo es importante no solo para definir nuestra identidad, sino también para procurarnos un obstáculo con respecto al cual medir nuestro sistema de valores y mostrar, al enfrentarlo, nuestro valor". Es por eso que el autor considera que "la figura del enemigo no puede ser abolida de los procesos de civilización” 
(Eco, 2011, p. 34). En otras palabras, parecería ser que los seres humanos necesitaran reconocerse como seres que necesitan un enemigo para poder definir su propia identidad colectiva.

En este fenómeno, dos dimensiones están en juego: por un lado, lo que Eco denomina la identificación de un enemigo que representa algún tipo de amenaza; por el otro, su construcción discursiva y su 'demonización'. Ambos son procesos de naturaleza inherentemente semiótica, aunque difieran en sus mecanismos básicos: mientras que el primero es más bien denotativo -es decir, se relaciona con la identificación y la segmentación de la realidad en unidades menores mediante una articulación de actores colectivos que está anclada en los pronombres 'Nosotros' y 'Ellos'-, el segundo es más bien connotativo, ya que se trata de un proceso activo e intencional de representación $-y$, al mismo tiempo, de construcción semiótica-, más relacionado con valores y emociones, ya que el enemigo no debe ser únicamente identificado y reconocido, sino también temido. Como se argumentó en la sección precedente, la construcción social del coronavirus incluyó estos dos procesos.

Respecto al primer proceso, la construcción del 'Otro' como un actor que es distinto de 'Nosotros' requiere establecer una frontera o límite que separe estas dos porciones de la realidad como unidades de significado distintas. En el caso de las identidades nacionales, la articulación de discursos en torno al significante 'Nosotros' solo tiene sentido si se identifican otras identidades que sean reconocidas y percibidas como diferentes de la propia. Esto refleja un mecanismo que ha sido ampliamente discutido en el campo político por Mouffe (2007), quien sostiene que las identidades (políticas) son siempre construidas discursivamente en torno a un eje que opone un 'Nosotros' a un 'Ellos' y que explica el inescapable carácter conflictivo y polémico del campo político, que conduce a la creación de identidades colectivas imaginadas, cuya articulación discursiva se basa en un conjunto limitado de propiedades que son consideradas comunes a todos los miembros individuales de ese grupo imaginado. La construcción discursiva e imaginaria del 'Otro' es, entonces, un proceso de naturaleza inherentemente semiótica, consistente en una segmentación del mundo percibido en unidades de sentido distintivas (Hjelmslev, 1943; Eco, 2000), a las que posteriormente se les 'da vida' mediante un conjunto de dinámicas -incluidas unas de naturaleza semiótica-que implican la creación de textos y discursos basados en códigos culturales específicos, de naturaleza tanto ética como estética. En esta segunda fase, ocurre una atribución de sentido, en diferentes niveles, a las unidades identificadas durante la primera fase, lo que resulta en el establecimiento de connotaciones, metáforas y otras representaciones, normalmente estructuradas en torno a un eje que oscila entre el 'bien' y el 'mal' (Mouffe, 2007). Dado que estos procesos de construcción del enemigo están fuertemente influenciados por códigos, imaginarios y normas culturales, parecería ser que, como propone Eco (2011, p. 16),

desde el principio se construyen como enemigos no tanto a los que son diferentes y que nos amenazan directamente [...], sino a aquellos que alguien tiene interés en representar como amenazadores aunque no nos amenacen directamente, de modo que lo que ponga de relieve su diversidad no sea su carácter de amenaza, sino que sea su diversidad misma la que se convierta en señal de amenaza.

Si bien, en Construir al enemigo, Eco estudia ejemplos históricos en los que seres humanos son imaginados y representados como 'el enemigo' mediante el empleo de descripciones, connotaciones y otras asociaciones, sus reflexiones se apoyan en unos mecanismos de naturaleza semiótica que también pueden utilizarse para comprender la construcción de enemigos de otro tipo, como el coronavirus. En el ensayo, Eco (2011, p. 34) sostiene que, en algunos casos, "se desplaza la imagen del enemigo de un objeto humano a una fuerza natural o social que de alguna forma nos amenaza y que debe 
ser doblegada, ya sea la explotación capitalista, la contaminación ambiental o el hambre en el Tercer Mundo". Este tipo de procesos, en los que se construye un enemigo no-humano, ocurre, por ejemplo, cuando catástrofes naturales, como terremotos o tsunamis, impactan una ciudad, un país o una región. En casos como estos, no es extraño atestiguar la emergencia de narrativas articuladas en torno a la idea de una Naturaleza -o la Madre Tierra- enojada. Como se argumentó en las páginas precedentes, la lista presentada por Eco podría incluir también a los virus y otras entidades biológicas que tienen un impacto en la salud humana.

Desde una perspectiva semiótica, entonces, una vez que el rol del enemigo ha sido construido a partir de un proceso de segmentación y diferenciación ('el coronavirus es diferente de otros virus') y ubicado en una estructura narrativa ('el coronavirus es una seria amenaza para la salud humana'), necesita ser 'dotado de vida' en términos discursivos, narrativos y visuales, para lo que se recurre a diferentes mecanismos. Este mecanismo ocurre al crear personajes en historias ficcionales, al lidiar con identidades colectivas relacionadas con individuos 'reales' que son percibidos como amenazas -como, por ejemplo, 'los inmigrantes' (Moreno Barreneche, 2020c) - y, como se intentó demostrar aquí, al lidiar con enemigos pertenecientes al reino natural, como el coronavirus.

\section{Conclusiones}

En su libro Kant y el ornitorrinco, Umberto Eco (1999, p. 69) escribe que "ante el fenómeno desconocido, a menudo se reacciona por aproximación: se busca ese recorte de contenido, ya presente en nuestra enciclopedia, que de alguna manera consiga dar razón del hecho nuevo". Para ejemplificar este principio, el semiotista italiano hace referencia al momento en que Marco Polo vio, en Java, un rinoceronte por primera vez y le atribuyó sentido asumiendo que se trataba de un unicornio. El caso específico sobre cómo la humanidad le ha atribuido sentido al coronavirus, una criatura biológica invisible que ha tenido consecuencias devastadoras a lo largo y ancho del mundo, no parecería ser la excepción: como se ha demostrado en las páginas precedentes, las categorías ya conocidas del 'monstruo' y la 'guerra' fueron utilizadas como metáforas para atribuir sentido a algo que era desconocido hasta el momento de la aparición del virus.

El objetivo de este artículo fue discutir desde una perspectiva semiótica las representaciones que, durante la pandemia del COVID-19, presentaron al coronavirus de manera negativa $\mathrm{y}$, concretamente, como un enemigo de la humanidad. La premisa subyacente a este tipo de investigación es que las representaciones cumplen un papel fundamental en cómo se moldean las percepciones y los imaginarios sociales, un proceso que toma la forma de narrativas específicas, en las que se crean discursivamente actores, junto con los roles específicos que estos desempeñan. Como se puede apreciar, el modo de representación estudiado en este artículo refleja de manera clara un conjunto de imaginarios y discursos fuertemente axiologizados, que fueron (y son) muy comunes durante la pandemia. Así, se podría establecer una distinción entre dos modos generales de representar al reino natural: uno más científico; el otro, más creativo.

A las representaciones que fueron arbitrariamente seleccionadas para el análisis llevado a cabo en este artículo podrían agregarse otras. Sin embargo, dado que el objetivo de la investigación semiótica, más que cuantitativo, es interpretativo y radica en estudiar cómo el sentido emerge a partir de unas estructuras subyacentes específicas que son expresadas mediante el empleo de recursos semióticos, las representaciones aquí discutidas parecerían bastar para postular un modo general de representación del coronavirus como un monstruo malvado que es un enemigo de la humanidad. Por supuesto que este es solamente un modo de representación entre otros, en los que el foco estuvo puesto en otros aspectos de la pandemia, como las teorías conspirativas que lo relacionaron con el desarrollo de la tecnología $5 \mathrm{G}$ o con unos intereses y unas estrategias políticas y económicas. En otras palabras: no se da por descontado que el modo de 
representación y construcción del coronavirus discutido en este artículo sea el dominante: este tipo de afirmación requeriría un enfoque metodológico diferente, que queda por fuera del alcance de la investigación semiótica.

Futuras investigaciones en este campo podrían profundizar respecto a los insights presentados en este artículo. Por ejemplo, se podría realizar un mapeo sistemático de las diferentes representaciones del coronavirus que circularon tanto online como offline durante la primera mitad del año 2020 (y posteriormente), para compararlas y relacionarlas entre sí. Por otra parte, se podría rastrear y analizar desde una perspectiva semiótica casos de representaciones divergentes. Algunas preguntas guía para estos futuros trabajos son las siguientes: ¿Cómo ha sido representado el virus en distintos países y por diferentes actores institucionales? ¿Pueden leerse estas representaciones a la luz de los intereses políticos y/o ideológicos de quienes las enunciaron? El objetivo de la semiótica -y, especialmente, de la sociosemiótica- es volver 'visible lo invisible', es decir, rastrear las condiciones de posibilidad de la significación y de la atribución de sentido, a través del análisis de productos específicos que, de un modo $\mathrm{u}$ otro, tienen sentido para un individuo o para un grupo. Tal ha sido el objetivo de este artículo, especificamente a través del examen de cómo se le atribuyó sentido al coronavirus mediante el uso de la metáfora del monstruo malvado con quien la humanidad está en guerra.

\section{Referencias}

'If I get corona, I get corona': the Americans who wish they'd taken Covid-19 seriously. (28 de marzo de 2020). The Guardian. Recuperado de https://www.theguardian.com/lifeandstyle/2020/ mar/28/americans-who-dont-take-coronavirus-seriously

Andacht, F. (6 de junio de 2020). El nada discreto desencanto de la unanimidad. eXtramuros, 2. Recuperado de https://extramurosrevista.org/el-nada-discreto-desencanto-de-la-unanimidad/

Arfuch, L. (Ed.) (2005). Identidades, sujetos, subjetividades. Buenos Aires, Argentina: Prometeo.
Battistelli, F. (2020). Coronavirus: metafore di guerra e confusione di concetti. MicroMega. Recuperado de http://temi.repubblica. it/micromega-online/coronavirus-metafore-di-guerra-e-confusione-di-concetti/

Berger, P., y Luckmann, T. (1966). La construcción social de la realidad. Buenos Aires, Argentina: Amorrortu.

Bitonte, M. E. (2008). La socio-semiótica como forma de pensamiento crítico. De la teoria al trabajo sobre configuraciones materiales. Perspectivas de la comunicación, 1(2), 59-71.

Cassandro, D. (22 de marzo de 2020). Siamo in guerra! II coronavirus e le sue metafore. Internazionale. Recuperado de https:// www.internazionale.it/opinione/daniele-cassandro/2020/03/22/ coronavirus-metafore-guerra

Demaria, C. (2019). Teoria digenere. Femminismi e semiotica. Milán, Italia: Bompiani.

Demuru, P. (2017). Praticas de vida. Entre semiótica, comunicação e política. Estudos semióticos, 13(1), 28-39.

Descola, P. (2005). Par-delà nature et culture. París, Francia: Gallimard.

Eco, U. (1999). Kant y el ornitorrinco. Barcelona, España: Lumen.

Eco, U. (2000). Tratado de semiótica general. Barcelona, España: Lumen.

Eco, U. (2011). Construir al enemigo y otros escritos. Barcelona, España: Lumen.

European Comission. (2020). WEBINAR: Covid-19 health response package. Recuperado de https://ec.europa.eu/cyprus/events/20201029_1_en

Evil Coronavirus (COVID-19). Cartoon Character of Pathogenic Bacteria In A Prohibited Symbol [Fotografia]. (2020). 123RF. Recuperado de https://es.123rf.com/photo_142342030_ evil-coronavirus-COVID-19-cartoon-character-of-pathogenic-bacteria-in-a-prohibited-symbol-vector-ill.html

Fabbri, P. (1998). El giro semiótico. Barcelona, España: Gedisa.

Fontanille, J. (2008). Pratiques sémiotiques. París, Francia: Presses Universitaires de France.

Fontanille, J. (2015a). Formes de vie: des jeux de langage à la phénoménologie des cultures. Metodo. International Studies in Phenomenology and Philosophy, 3(1), 21-40.

Fontanille, J. (2015b). Formes de vie. Lieja, Bélgica: Presses Universitaires de Liège. 
Forster, V. (20 de abril de 2020). There Is A Coronavirus Coloring Book Designed To Help Children Cope With The Pandemic. Forbes. Recuperado de https://www.forbes.com/sites/victoriaforster/2020/04/02/there-is-a-coronavirus-coloringbook-designed-to-help-children-cope-with-the-pandemic/\#2d1676333ca5

Free-Lanced in Lockdown. (5 de Agosto de 2020). Safrea Chronicle. Recuperado de https://safreachronicle.co.za/free-\%E2\%80\%95-lanced-in-lockdown/

Geertz, C. (1973). The Interpretation of Cultures. Nueva York, NY: Basic Books.

Giaimo, C. (1 de abril de 2020). The Spiky Blob Seen Around the World. The New York Times. Recuperado de https://www.nytimes.com/2020/04/01/health/coronavirus-illustration-cdc. $\mathrm{html}$

Greimas, A. J. (1984). Sémiotique figurative et sémiotique plastique. Actes sémiotiques, 6(60), 05-24.

Greimas, A. J., y Courtès, J. (1979). Sémiotique. Dictionnaire raisonné de la théorie du langage. París, Francia: Hachette.

Hauser, D. J., y Schwarz, N. (2019). The War on Prevention II: Battle Metaphors Undermine Cancer Treatment and Prevention and Do Not Increase Vigilance. Health Communication. DOI: 10. 1080/10410236.2019.1663465

Hénault, A. (2012). Les enjeux de la sémiotique. París, Francia: Presses Universitaires de France.

Heroes of the Front Lines. Stories of the Courageous Workers Risking their Own Lives to Save Ours. (2020). Time. Recuperado de https://time.com/collection/coronavirus-heroes/

Hjelmslev, L. (1943). Prolegomena to a Theory of Language. Madison, WI: Wisconsin University Press.

Homer, B. D., y Plass, J. L. (2009). Expertise reversal for iconic representations in science visualizations. Instructional Science, 38, 256-276.

House of European History. (2020). History in the Making: Documenting Covid. Sarah Fighting Corona Virus [Ilustración]. Recuperado de https://historia-europa.ep.eu/en/history-making-documenting-covid?fbclid=I wAR-1 mUNyzwB6k0Ru-
KEQn703fRd6-m8k-gXNhNT2aLbm0uvlw5A4b-4U-9yNI

Jasso, M. (3 de abril de 2020). \#EnFotos: El coronavirus 'se propaga' en forma de piñata [Fotografia]. Expansión. Recuperado de https://politica.expansion.mx/cdmx/2020/04/03/ enfotos-el-coronavirus-se-propaga-en-forma-de-pinata\#pid=slide-0

Koschorke, A. (2009). Zur Epistemologie der Natur/Kultur-Grenze und zu ihren disziplinären Folgen. Deutsche Vierteljahrsschrift für Literaturwissenschaft und Geistesgeschicte, 83(1), 9-25.

Lakoff, G., y Johnson, M. (1986). Metáforas de la vida cotidiana. Madrid, España: Cátedra.

Landowski, E. (1997). Présences de I'autre. París, Francia: Presses Universitaires de France.

Landowski, E. (2014). Sociossemiótica: uma teoria geral do sentido. Galáxia, 27, 10-20.

Landowski, E. (2016a). A prueba del otro. Contratexto, 26, 13-29.

Landowski, E. (2016b). Interacciones arriesgadas. Lima, Perú: Fondo Editorial de la Universidad de Lima.

Landowski, E. (2019). Politiques de la sémiotique. Rivista Italiana di Filosofia del Linguaggio, 13(2), 6-25.

Made in Casa Piñatas Perú. (2020). Piñata Virus [Fotografía]. Pinterest. Recuperado de inttps://www.pinterest.com/ pin/646125877778828622/.

Ministerio de Salud Pública. (2020). Plan Nacional Coronavirus. Recuperado de https://www.gub.uy/salud

Moreno Barreneche, S. (2020a). Somebody to Blame. On the Construction of the Other in the Context of the COVID-19. Society Register, 4(2), 19-32.

Moreno Barreneche, S. (2020b). Mind the Gap! On the Discursive Construction of Collective Political Identities. Punctum, 6(2), 11-27.

Moreno Barreneche, S. (2020c). Migración y 'cultura del miedo': estudio sociosemiótico. Estudios, 43, 65-82.

Moreno Barreneche, S. (2021). Los héroes de la pandemia: la construcción discursiva del colectivo de 'los trabajadores sanitarios' durante la crisis del COVID-19. CS, 33, 75-101. 
Mouffe, C. (2007). En torno a lo político. Ciudad de México, México: Fondo de Cultura Económica.

Naciones Unidas. (2020). Information from the UN System. Recuperado de https://www.un.org/en/coronavirus/information-un-system

Onuf, N. (1989). A World of Our Making. Columbia, SC: University of South Carolina Press.

Pacheco Miranda, T., y Pinto da Costa, I. (19 de junio de 2020). Eis o mural de Vhils no Hospital de São João. Porque "os profissionais de saúde também precisam de ser cuidados". Público. Recuperado de https://www.publico.pt/2020/06/19/ p3/noticia/eis-mural-vhils-hospital-sao-joao-profissionais-saude-tambem-precisam-cuidados-1921173

Paolucci, C. (2012). Sens et cognition. La narrativité entre sémiotique et sciences cognitive. Signata, 3, 299-316.

Paolucci, C. (2020). Cognitive Semiotics. Integrating Signs, Minds, Meaning and Cognition. Berlín, Alemania/Nueva York, NY: Springer.

Peruzzo, N., y Rodríguez Juele, A. (2020). Coco \& Fran contra el coronavirus. Guía informativa de Covid-19. Montevideo, Uruguay: Bandas Educativas/Instituto Clemente Estable. Recuperado de https://www.comicbacterias.com/wp-content/ uploads/2020/05/Coco-y-Fran-contra-el-Coronavirus.pdf

Propp, V. (2000). Morfología del cuento. Madrid, España: Fundamentos.

Searle, J. (1995). The Construction of Social Reality. Londres, Reino Unido: Penguin.

Sontag, S. (1978). IIIness as Metaphor. Nueva York, NY: Farrar, Straus and Giroux.

Talbot, N. (10 de abril de 2020). Corona Diaries: Branding the Spiky Blob. Medium.com.Recuperado de https://medium.com/@niccitalbot/corona-diaries-branding-the-spiky-blob-b2942df2906b

Testa, A. (30 de marzo de 2020). Smettiamo di dire che è una guerra. Internazionale. Recuperado de https://www.inter- nazionale.it/opinione/annamaria-testa/2020/03/30/metafora-guerra-coronavirus

The aliens among us. How viruses shape the world. (22 de Agosto de 2020). The Economist. Recuperado de https://www.economist.com/leaders/2020/08/22/how-viruses-shape-the-world

The European Research Council Magazine. (10 de marzo de 2020). Coronavirus: What's beyond the science frontier. Recuperado de https://erc.europa.eu/news-events/magazine/coronavirus-what-s-beyond-science-frontier

Traini, S. (2006). Le due vie della semiotica. Teorie strutturali e interpretative. Milán, Italia: Bompiani.

Van Leeuwen, T. (2005). Introducing Social Semiotics. Londres, Reino Unido: Routledge.

Verón, E. (1981). Construir el acontecimiento. Barcelona, España: Gedisa.

Verón, E. (1988). La semiosis social. Barcelona, España: Gedisa.

Violi, P. (2017). Due vie per la semiotica o un incrocio di sguardi? Algirdas Greimas e Umberto Eco a confronto. Entornos, 30(1), 25-33.

Contribución autoral

a) Concepción y diseño del trabajo; b) Adquisición de datos; c) Análisis e interpretación de datos; d) Redacción del manuscrito; e) revisión crítica del manuscrito.

S. M. B. ha contribuido en $a, b, c, d, e$.

Editor responsable: L. D. 